\title{
Policy in focus: fee-for-service woes, record health spending, and earlier HPV vaccination cuts cancer risk
}

\author{
- Cite as: CMAJ 2021 December 6;193:E1848-9. doi: 10.1503/cmaj.1095978
}

Posted on cmajnews.com on November 23, 2021

A lack of alternative payment schemes may discourage some early-career family doctors from providing traditional cradle-to-grave care, according to a commentary in Canadian Family Physician.

According to Dr. Goldis Mitra and coauthors, initial results from a small study of 63 early-career family physicians across Canada suggest that the availability of alternatives to fee-for-service payment plans may be an important factor shaping practice choices.

In regions where fee-for-service was the only payment option, many of the doctors interviewed reported pursuing serial locums and focused areas of practice - even if their first preference was longitudinal primary care.

Some of the doctors cited concerns about burnout and the "unsustainable demands" of fee-for-service-based comprehensive family medicine. Others told researchers that the emphasis on volume under fee-for-service schemes "impeded their ability to provide highquality medical care in alignment with their values."

According to Mitra, working under a salaried payment model can also reduce the administrative burden of running a practice.

Provincial governments have piloted a patchwork of alternative payment schemes over the past two decades - from salaried models that pay physicians a fixed amount per patient, to blended models that combine capitation and fee-for-service. But high upfront costs and government concerns about physician productivity under alternative payment plans remain hurdles to wider implementation.

In Alberta, a 2019 evaluation of two interprofessional primary care clinics that operate under a salaried model found that the practices cost more than usual to set up but ultimately saved the province close to $\$ 120$ million over 10 years - largely because the clinics' patients required less hospital care than other patients.

The pandemic has led to renewed calls for alternative payment models as many fee-for-service physicians faced financial instability during service shutdowns.

Meanwhile, family medicine has struggled to attract medical graduates to its ranks, and increasing numbers of family doctors are narrowing their practices to focus on niche interests.

According to Mitra and coauthors, provincial and territorial governments and medical associations should carefully adapt how they fund primary care or "risk eroding comprehensive practice even further."

\section{Health care spending on the rise}

- Expensive medications for rare diseases continue to drive up public drug spending, according to a report by the Patented Medicine Prices Review Board looking at 2019-20 data from every province except Quebec, as well as some federal and territorial plans. Spending by public drug plans rose $3.7 \%$ to \$12.5 billion in 2019-20, with just 5\% of beneficiaries accounting for almost $60 \%$ of expenditures. The 10 most expensive drugs were all treatments for rare diseases that came with annual price tags of more than $\$ 100000$.
- A report from the Canadian Institute for Health Information (CIHI) shows that Canada is on track to spend a record $\$ 308$ billion on health care in 2021. Total spending increased by an estimated 12\% between 2019 and 2020 - three times the annual growth seen between 2015 and 2019. In a news release, $\mathrm{CIHI}$ president and CEO David O'Toole noted that the COVID-19 pandemic has contributed to the single biggest increase in health spending in at least 30 years. A new pandemic spending category, which includes expenditures on treatment, contact tracing and vaccinations, is expected to account for $\$ 23$ billion or $7 \%$ of total health care spending in 2021. The pandemic also shifted the balance of public and private spending on health care. While the public sector has typically covered about $70 \%$ of health care costs since the early 2000 s, that share is expected to climb to $75 \%$ in 2021.

- $\mathrm{ClHI}$ for the first time included spending data on home care and community care in the National Health Expenditure Database. In 2020-21, a little over 5\% of provincial health care spending went toward home and community care, compared to $11 \%$ toward long-term care in institutions. In a commentary on the report, Colin Busby of the Institute for Research on Public Policy said reporting these data will be key to advancing health reform. Canadian provinces invest between $22 \%$ and $42 \%$ of their continuing care budgets in home and community care, compared to $60 \%$ in Denmark, a world leader in this area. Busby noted the data spark 
questions about differences in spending among the provinces, and difficulties shifting care away from institutions. "These new home and community care data should launch and enrich the policy discussions around these pressing issues," he said.

\section{HPV vaccine cuts cancer risk}

- Research in The Lancet showed that a national human papillomavirus (HPV) vaccination program has virtually eliminated cervical cancer in British women under age 26 - although it's worth noting that such cancers usually occur later in life. Researchers at King's College London found the biggest reductions in risk were among girls who were vaccinated at younger ages. Vaccination against HPV at ages 12 and 13 reduced the relative risk of cancer by $87 \%$, compared to $62 \%$ for those vaccinated at ages 14-16, and $34 \%$ for those vaccinated at ages 16-18. Dr. Amanda Selk, an obstetriciangynecologist at Mount Sinai Hospital in Toronto who is also president of the Society of Canadian Colposcopists, said the study results are exciting because they're the first to show that the HPV vaccine prevents cancer - not just precancers.

- In October, experts warned that Canada is losing ground on HPV vaccinations. Canada was on track to eliminate cervical cancer by 2040 until the pandemic disrupted delivery of school-based HPV vaccination programs. Now, a huge "catch up" effort will be required to hit that target, warned Dr. Jennifer Blake of the Society of Obstetricians and Gynecologists of Canada. According to Dr. Vivien Brown, past president of the Federation of Medical Women of Canada, overwhelmed public health units often paused school vaccination programs during the pandemic. In Alberta, less than $10 \%$ of eligible 12-year-old girls got a second dose of the HPV vaccine in 2020 , compared to $65.5 \%$ in 2019. Similarly, in Northern Ontario, Sudbury's public health unit administered 1237 doses of the HPV vaccine in 2020, down from 3325 doses the previous year.

- Meanwhile, a cross-sectional American study published in JAMA Network Open found that nearly a quarter of American women who were not vaccinated against HPV had not been screened for cervical cancer, and $29 \%$ reported they were not up to date on screening. The authors noted the findings were concerning considering "declining cervical cancer screening uptake, recent stabilization in cervical cancer incidence, and the COVID-19 pandemic, which has further exacerbated HPV vaccination and cervical cancer screening rates."

\section{Other population health and policy news:}

- Reducing systolic blood pressure by a modest $5 \mathrm{~mm} \mathrm{Hg}$ cuts the risk of type 2 diabetes by $11 \%$, according to a metaanalysis of 19 randomized controlled trials. The study, published in The Lancet, also found that angiotensinconverting-enzyme (ACE) inhibitors and angiotensin II receptor blockers (ARBs) - two of the most common and least expensive blood pressure medications - reduced patients' risk of developing type 2 diabetes by $16 \%$. However, beta blockers and thiazide diuretics increased the risk. In a related commentary also published in The Lancet, Drs. Matthew Cavender and Robert Wirka of the University of North Carolina argued the findings suggest that "earlier, more aggressive lowering of blood pressure, with an emphasis on renin-angiotensinaldosterone system inhibitors, can decrease the incidence of diabetes."

- British Columbia is asking Health Canada to decriminalize possession of small amounts of illegal drugs for personal use in a bid to stem overdose deaths. The province is the first to apply for such an exemption under Canada's Controlled Drugs and Substances Act. If granted, BC residents older than 19 would be allowed to hold up to $4.5 \mathrm{~g}$ of illegal substances. According to Sheila Malcolmson, Mental Health and Addictions minister in $\mathrm{BC}$, removing criminal penalties is key to addressing the province's overdose crisis. "Shame and fear keep people from accessing life-saving services and treatments," she explained.

- Recent immigrants at the end of their lives are more likely to receive intensive care and die in hospital than other
Canadians, according to research published in JAMA Network Open. In the last 90 days of life, recent immigrants spent nearly twice as many days in intensive care as other patients, and nearly half as many days in long-term care. Although recent immigrants' endof-life preferences may differ from those of other Canadians, the study authors suggest their findings point to the need for "more culturally appropriate care interventions for immigrants."

- Older psychiatric inpatients are more likely to receive pharmacological or physical restraints in non-emergency situations than younger patients, according to Canadian research in Frontiers in Psychiatry. The study, based on data from Ontario psychiatric hospitals between 2005 and 2018 , found that use of restraints on patients aged 85 and older was 1.6 times higher than for patients aged 45-64 (13.3\% compared to $8.3 \%$ ). The authors said the findings were "concerning" and recommended that nonpharmacological, person-centred management strategies should be considered instead.

- Using antipsychotic drugs during pregnancy does not increase the risk of some birth complications and neurodevelopmental disorders, according to a population-based cohort study in JAMA Internal Medicine. The findings suggest that prenatal exposure to antipsychotics does not increase the risk of attention-deficit/hyperactivity disorder, autism spectrum disorder, or babies being small for gestational age. Initially, researchers found a small increased risk of preterm birth, but additional analyses (including comparing those exposed to antipsychotics in the womb to siblings who were not exposed) did not support an increased risk.

\section{Greg Basky, Saskatoon, Sask.}

Content licence: This is an Open Access article distributed in accordance with the terms of the Creative Commons Attribution (CC BY-NC-ND 4.0) licence, which permits use, distribution and reproduction in any medium, provided that the original publication is properly cited, the use is noncommercial (i.e., research or educational use), and no modifications or adaptations are made. See: https://creativecommons.org/ licenses/by-nc-nd/4.0/ 